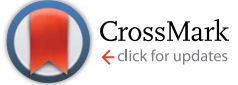

Cite this: Food Funct., 2014, 5, 1686

\title{
Sensory attributes of soft drinks and their influence on consumers' preferences
}

\author{
Noemí Redondo, Sonia Gómez-Martínez and Ascensión Marcos* \\ Soft drinks are beverages composed of water and other ingredients that provide specific sensorial attributes. \\ Soft drink consumption patterns have recently been changed partially influenced by an increased availability \\ of different types of beverages during the last few years. Consumers' preferences to choose one drink over \\ another are influenced, not only by genetic, psychological and environmental factors, but also by the \\ beverage's specific attributes. In fact, beverage consumption is driven by the sensations it gives. Because \\ the main component of soft drinks is water, an increase in the intake of soft drinks might improve fluid \\ intake and the levels of water in the body if it is regarded as an "essential nutrient".
}

Received 3rd March 2014

Accepted 17th May 2014

DOI: $10.1039 / \mathrm{c} 4 \mathrm{fo} 00181 \mathrm{~h}$

www.rsc.org/foodfunction

number of beverages available in 2002. For example, the

\section{Consumption of soft drinks}

A soft drink is the name commonly given to a non-alcoholic carbonated or non-carbonated beverage containing caloric sweeteners and flavorings. ${ }^{1}$ The preparation and processing of a soft drink includes several stages, beginning with the treatment of the water used in this process. The next step is the preparation of a simple sugar syrup, the ingredient that provides the taste of the beverage, followed by the addition of several ingredients to the simple sugar syrup in order to obtain the final syrup: glucose or fructose, aromatic compounds, vitamins, minerals and other food additives, such as acidulants, colorants or preservatives. Finally, the completed beverage is obtained as a mixture of the final syrup, the treated water and the carbonic gas (in carbonated drinks). ${ }^{2}$ As a result, all soft drinks have a basic compositional structure: water, considered an essential nutrien $\mathrm{t}^{3}$ and the main component that makes up about 87$92 \%$ of the beverage, and the sweetener, which represents about $8-12 \%$ of the beverage by mass. Another common ingredient in almost all soft drinks is the acidulant, which is any organic or inorganic acid that contributes to the sourness of the beverage. The balance between sweetness and sourness is the basic typical taste profile of all flavored soft drinks. ${ }^{4}$

The wide range of new beverages that have emerged (some of them sugar-sweetened, caffeinated or often both, others with reduced caloric levels or with a range of different flavors or other food ingredients added) makes it difficult to understand the beverage consumption patterns. ${ }^{5}$ Beverage consumption patterns of American adults in 2002 were different and more complex than those obtained in 1977 , because of the greater

Immunonutrition Research Group, Department of Metabolism and Nutrition, Institute of Food Science and Technology and Nutrition (ICTAN), Spanish National Research Council (CSIC), Jose Antonio Novais Street, 10, 28040, Madrid, Spain. E-mail: amarcos@ictan.csic.es; Fax:+34 915493627; Tel: +34915492300 ext. 231210 drinking patterns which were dominated by soda in 2002 were less frequently observed in 1977, while a larger proportion of the population in 1977 showed drinking patterns that were dominated by whole-fat milk and coffee, giving an additional insight into how consumption has changed over time. In addition, there was an increase of $20 \%$ in consumers reporting soda consumption and $14 \%$ more consumers of diet beverages in 2002 compared to 1965, showing an increase in the consumption of soda beverages across almost three decades. ${ }^{6}$ The Healthy Lifestyle in Europe by Nutrition in Adolescence Cross Sectional Study (HELENA-CSS), which evaluates the amounts of beverages consumed among adolescents aged 12.517.5 across urban areas from 10 European cities, showed that sugar-sweetened beverages were the second most consumed beverages ( $430 \mathrm{ml}$ per day) after water, which is the largest contributor to fluid consumption $(821 \mathrm{ml}$ per day) in adolescents. ${ }^{7}$

Although fluid intake is not closely associated with hydration status, it is commonly used as an approximate measure of hydration because it is easy to measure.$^{8}$ Recent statements on water requirements have been based on retrospective recalls of water intake from food and beverages among healthy populations. ${ }^{9,10}$ Indeed, the European Food Safety Authority (EFSA) established in 2010 an adequate total water intake (TWI) as 2.0 and $2.5 \mathrm{~L}$ per day for females and males, respectively, and reported that TWI should include water from drinking water, all kind of beverages and high-water-content food. ${ }^{11}$ In fact, water intake depends to some extent on dietary choices and eating/ drinking habits. ${ }^{12}$ This outcome has been observed in several studies from Europe and the USA, which show that around 70$80 \%$ of the TWI has been estimated to be supplied from beverages of different types (including water, tea and coffee, milk, soft drinks, juices and alcoholic drinks), including water from food. ${ }^{13}$ 
There are many reasons to drink beverages, but most of our drinking is due to physiological thirst caused by a hydrationdeficient status. However, beverages are not only consumed for quenching the thirst, as shown in individuals asked to drink pure water instead of the beverages they used to drink, which revealed that the same drinkers were in fact hypodipsic or with reduced thirst. Therefore, beverages are consumed not only for refreshment during warm weather or for quenching the thirst, ${ }^{\mathbf{1 4}}$ but also by reason of a "linking" behavior, because of the taste of the beverage ${ }^{15}$ and because of the desire to drink. ${ }^{16}$

In addition, there is some evidence that drinking patterns seem to be mediated by the taste buds, which communicate with the brain by mechanisms that are still not well understood. This trend in human behavior of rehydration may be advantageous because it allows the replacement of water losses before dehydration takes place. ${ }^{\mathbf{1 4}}$ In fact, a permanent status of optimal hydration is recognized to provide health benefits ${ }^{\mathbf{1 7}}$ and water balance has been reported to promote health, prevent disease and be linked to optimal physical and cognitive performance, ${ }^{\mathbf{1 0}}$ while dehydration has the opposite effects. ${ }^{18}$

The present review tries to update the knowledge about the sensory attributes of soft drinks that may influence the preference patterns for particular beverages, and therefore, their consumption.

\section{Sensory attributes of soft drinks}

The individual experience during eating or drinking something results in a multitude of sensations, including taste, smell and touch, as well as temperature, sight, sound and sometimes pain or irritation. This multi-sensory experience supports the perception of flavor. ${ }^{19}$ Both the flavor and the mouthfeel sensations of beverages are factors that contribute to its success, agreeing with a recent study performed on 201 habitual consumers of regular and diet carbonated beverages, in which $80.6 \%$ of consumers agreed that flavor was the most important reason to choose one beverage over another. This outcome could suggest that either the flavor or taste of a beverage may be a vital aspect leading to a certain consumption pattern..$^{20}$

There are several sensorial systems involved in the perception of flavor (gustatory, trigeminal, oral, olfactory and vision). The gustatory sense specifically refers to the well-known five basic sensations of sweet, sour, salty, bitter and umami (savory) ${ }^{21}$ (Fig. 1). Taste occurs when chemicals come into contact with the taste receptors on the tongue, palate, throat, epiglottis or esophagus, which send signals to the brain and represents the interplay between the oral environment and the nervous system. ${ }^{22}$ They have been extensively studied, especially to determinate whether they are expressed in tissues outside of the mouth, and as a result sweet and bitter receptors have been identified in the gut. ${ }^{23}$ Taste receptors lie side by side in the oral cavity with thermoreceptors, mechanoreceptors, and nociceptors ${ }^{\mathbf{2 4 , 2 5}}$ which transmit information to the brain on the food's texture, weight and temperature, mainly via the trigeminal system. ${ }^{26}$ This could mean that everything that is tasted induces tactile and thermal sensations, and sometimes even chemesthetic sensations, such as burning and stinging. ${ }^{22}$ The trigeminal system involves the fifth cranial nerve that innervates most of the face and comprises three main branches relevant to flavor: ophthalmic, mandibular, and maxillary. ${ }^{27}$ Oral touch sensations or mouthfeel are defined as "a mixed experience deriving from sensations in the oral cavity that are related to physical or chemical properties of a stimulus by a material". ${ }^{28}$ Smoothness, body and mouth coating are the attributes that have been used to describe mouthfeel in beverages, ${ }^{29}$ body or tongue-heaviness ${ }^{30}$ being related to the denseness of the rheological structure and mouth coating being linked to the oral cavity coating. ${ }^{31}$ Both terms are related to the consumer's perception of drinkability. ${ }^{32}$ Although taste and oral somesthesis provide critical information about the physicochemical nature of ingested stimuli, the smell of a food is required for flavor identification. ${ }^{33}$ These feelings start in the nose when an odorant substance binds to the membrane of the olfactory cells, ${ }^{34}$ whose axons make synapses with neurons called mitral cells in the olfactory bulb. All these sources of information influence the overall perception of flavor ${ }^{35}$ (Fig. 1).

The different activations of these sensory systems constitute the multi-modal integration of flavor. Just before and during food intake, visual, gustatory, olfactory, tactile and auditory information is processed ${ }^{35}$ and integrated by the brain, resulting in the perception of flavor. ${ }^{19}$ Although these systems are obviously anatomically separated by diverse functions, they are not cognitively independent. ${ }^{27}$ This integration seems to be performed by a specific brain region called the orbitofrontal cortex, which receives projections from the olfactory cortex, the gustatory cortex and the face primary sensory cortex or trigeminal system, ${ }^{36}$ along with projections from the amygdala and the inferior temporal visual cortex. In fact, the orbitofrontal cortex is the first place in the brain where taste, smell, trigeminal information and vision can all interact (Fig. 1). In addition, some cells in the orbitofrontal cortex not only integrate the three components of flavor, but also react to the current cognitive aspects of food intake such as appetence or reward value, supporting the notion that this area of the brain center is responsible for the psychological notion of flavor. ${ }^{37}$

\section{Interaction and perception of sensorial attributes}

Vision seems to be the dominant modality in real time-evaluation of a product, because the product experience seems to be highly dependent on what we see. ${ }^{38}$ However, the immediate sensory feeling of foods is dominated by taste, smell and oral haptic perception, and these sensory attributes of a product can interact and impact on its flavour perception. This outcome may occur from physical interactions between components within the food or beverage matrix, leading to changes in volatile release $^{39}$ or viscosity, ${ }^{40}$ to multi-modal interactions resulting from cognitive or psychological integration of the anatomically separated sensory systems. ${ }^{41}$ Using aroma perception studies, the evidence of taste-aroma interactions 


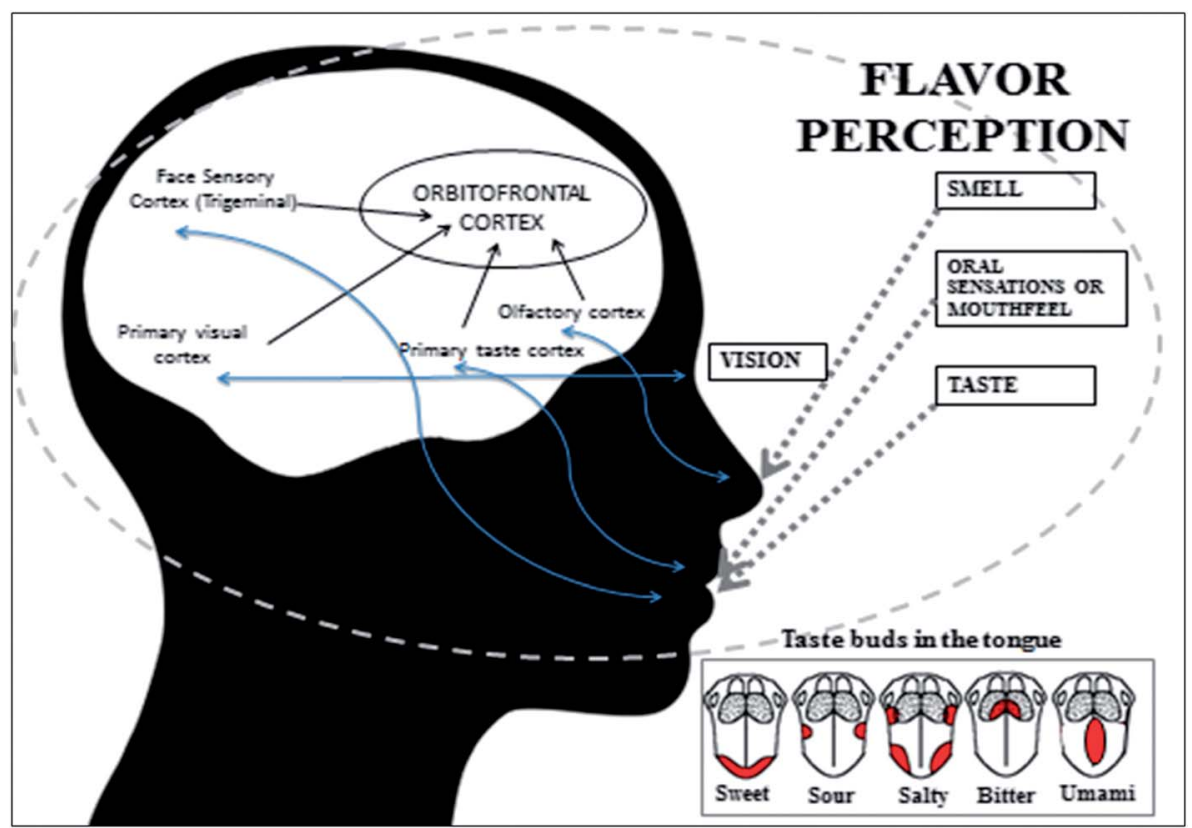

Fig. 1 Multimodal perception of flavor.

has been shown in model beverages with citral and limonene aromas which have had acids and sugars added to them. ${ }^{19}$ These so-called tastants have been shown to produce an increase of perceived citral flavor intensity. Carbonic acid and sugar have been reported to play a different role in mintflavored beverages, in which carbon dioxide $\left(\mathrm{CO}_{2}\right)$ has more impact than sugars in aroma release of mint-flavored compounds after carbonated beverages are consumed..$^{42}$ Aroma sensation is perceived more after the consumption of a carbonated beverage because of several changes produced in the mouth, such as contact with saliva, mouth temperature or biochemical reactions. ${ }^{43}$

The type of sweetener used in beverages also has an impact on mouthfeel and viscosity. Indeed, a combination of artificial sweeteners (aspartame and acesulfame potassium) has been shown to come closer to the mouthfeel perception provided by natural sugars than the use of a single sweetener (aspartame). ${ }^{44}$ In this case, diet cola beverages tend to have less mouth coating and lower viscosity than regular beverages, indicating that consumers can detect both attributes when sugar is removed from cola beverages. ${ }^{30}$ This outcome is in agreement with Shachman (2005), ${ }^{4}$ who suggested that this change in perceived mouthfeel is because of the thickening effect that nutritive sweetener has on the product. Something different is encountered between diet and regular lemon/lime beverages. These beverages have not been considered different in regards to mouth coating, compared to regular and diet cola beverages. The lemon/lime flavor profile could be masking the loss in mouthfeel differences in body and mouth coating compared to the cola flavor profile and it could probably be related to sweeteners and acid ingredients used in these lemon/lime beverages. $^{30}$

Sweeteners also impact on multiple sensory modalities when evaluating regular and diet lemon/lime beverages. Diet products tend to have lower tongue heaviness, sweet aftertaste, mouth coating, citrate flavor and slipperiness, and high bitter aftertaste, metallic aftertaste, burn and bite. All diet products differ in at least one of the aromatic/flavor attributes, which may be because of the flavor and mouthfeel adjustments using gums and high-intensity sweetener blends. ${ }^{45}$ Another ingredient used as a flavoring agent is caffeine, ${ }^{46}$ which has been reported to produce bitterness depending on the concentration $^{47}$ and can also interact with volatile flavor compounds, altering their solubility and modifying their perceived flavor impact. $^{48}$

Carbon dioxide $\left(\mathrm{CO}_{2}\right)$, as a specific ingredient of carbonated beverages, may also influence the multimodal sensory perception, because these beverages are dynamic systems with several ingredients. ${ }^{49}$ Indeed, $\mathrm{CO}_{2}$ is capable of producing differential features of mouthfeel: carbonation, as the feeling of small bubbles on the tongue and sides of the mouth while the sample is in the mouth; bite, as the stinging experienced in the oral cavity at the onset of exposure to carbon dioxide; burn, as the perception of increased temperature and irritation resulting from the exposure to carbon dioxide while the sample is in the mouth; numbing, as the perception of loss of feeling; and finally, astringency, as a mouth-drying sensation felt on the tongue and sides of the mouth while the sample is in the mouth. ${ }^{30}$ The oral sensations produced by these beverages could be due to a chemogenic origin, through the formation of carbonic acid, or/ and to a mechanical origin, from the capability of $\mathrm{CO}_{2}$ bubbles to stimulate tongue receptors. ${ }^{50,51}$ Carbonic acid initiates a trigeminal sensation of oral irritation, ${ }^{52}$ but it also impacts on gustatory and olfactory systems. ${ }^{19}$ This issue has been previously confirmed, ${ }^{53}$ showing that carbon dioxide in beverages can modify taste and flavour perception. Likewise, tingling and irritation sensations produced by carbonated beverages have been shown to be suppressed when high amounts of glucose are 
added, and this effect was higher at a low carbonation level. In addition, citric acid enhanced the bitter aftertaste produced by $\mathrm{CO}_{2}$ in carbonated beverages, ${ }^{54}$ suggesting that the effect of carbonation on flavor perception can be affected by the concentration of sweeteners and acids in the system. These components of the aqueous phase may also contribute to enhancing the effects of carbonation, affecting the bubble number and size, the bubble growth rate and the ascending bubble velocity due to the modification of the $\mathrm{CO}_{2}$ environment, and therefore affecting the sensory properties of these beverages. ${ }^{55}$

For other sensorial attributes related to flavor perception, vision can affect this multiple perception mainly by the effect of color on flavor. ${ }^{56}$ With regard to taste, more than three decades ago, Johnson et al. (1983) ${ }^{57}$ reported that sweetness increased linearly over all sucrose concentrations and over a narrow range of color intensities, showing that more intense colors result in the perception of a more intense sweet taste. This property of beverages also has an effect on carbonation. In clear beverages, such as lemon or lime drinks, bubbles are more easily seen and are perceived as having significantly more carbonation compared to cola beverages. This aspect might also have an impact on the fact that these lemon/lime beverages have been rated lower in mouth coating, sweet, sour and bitter after-feel, and they are usually perceived as more similar to water compared to the caramel-colored cola beverages. ${ }^{30}$ Temperature is another factor to take into account, since it also exerts an impact on the perception of taste, smell and flavor. ${ }^{57}$ Indeed, in sugar solutions, sweetness perception increases strongly with temperature. $^{58}$ However, it is important to highlight that temperature may affect not only the whole taste, but also the taste of specific compounds. In addition, temperature directly modulates the transduction of taste, leading to a dependent interaction between gustatory and thermal inputs. ${ }^{59}$ This outcome could be because of the fact that in the oral cavity there exists a co-activation of taste and somatosensory neurons that surrounds taste buds and includes some mechanoreceptors and chemoreceptors that transmit information to the brain about what we are eating/drinking. ${ }^{26}$

Although some sensations contribute to flavor perception more than others, all sensorial attributes have an impact on whether foods and drinks are liked or disliked ${ }^{3}$ and future research should focus on the determination of physical origins of key sensory attributes that can drive consumer liking and satisfaction. $^{20}$

\section{Development of preferences}

As mentioned previously, flavor involves the total sensory impression of foods and drinks and consequently it has a major influence on consumer preferences. The term "preference" refers to the selection of one item over others. Before birth, the foetus inhales and swallows the amniotic fluid at the third trimester, which contains nutrients and flavors coming from the mother's diet, ${ }^{60}$ being the first chemosensory experiences and the beginning of flavor learning. ${ }^{61}$ In this case, the foetus increases its swallowing in response to the introduction of sweet solutions in the amniotic fluid, but decreases the intake in response to bitter solutions ${ }^{62}$ and this outcome could reflect that preferences are innate. ${ }^{63}$

Tasting something sweet leads to the activation of pleasuregenerating brain circuitry. In fact, newborns have more relaxed faces accompanied with a smile after the intake of something sweet. ${ }^{64}$ This result is in agreement with other studies pointing out that children typically select the most intensely sweet taste and the pleasure response to the sweet taste is observed in individuals of all ages, races and cultures. ${ }^{65}$

However, several studies have shown that these initial preferences could be altered after birth via early experiences with food and eating during the first years of life. Parents' choices made at the beginning (for example feeding milk formula or breast-feeding) affect the development of food acceptance patterns in infants. ${ }^{\mathbf{6 6 , 6 7}}$ This fact could mean that early dietary patterns are important to drive an infant's preferences and might directly affect their dietary habits later in life. ${ }^{68}$

Liem and de Graaf (2004) ${ }^{69}$ studied the changes of taste preferences in 63 children aged 8-9 years and 46 young adults aged 22 years. Both groups were divided into two groups, a sweet group who consumed sweet orangeade and a sour group who consumed sour orangeade for 8 days. Children in the sweet group tended to consume more orangeade during the last day of the study than during the first day and their preferences for the sweet orangeade after the study were increased. In addition, children in the sweet group consumed more orangeade (184 \pm $28 \mathrm{ml}$ per day) than children in the sour group did $(150 \pm 58 \mathrm{ml}$ per day). However, adults in the sweet group decreased the consumption of orangeade during the last day of the study without changes in their taste preferences. This outcome could be because of the fact that young adults have already experienced these beverages in the past. Unlike the behavior observed with sweet orangeade, children did not increase their preference for the sour taste, which could be related to the fact that during childhood preferences for a sour taste are more stable than preferences for a sweet taste, and this agrees with some studies showing changes in sour preferences after a long term exposure (eight months). ${ }^{67}$ However, in a study performed by Sartor et al. ${ }^{70}$ adults who disliked sucrose, who had a low score in a sucrose preference test performed with different concentrations of this sugar, increased their preference for a sweet taste after a month in which they submitted to sweetened soft drink supplementation. The important implication of this taste change is that continuous sweetened beverage consumption could determine an explicit preference change for a sweet taste.

In summary, although preferences are innate, their development is associated with the interaction between genetic predisposition and environmental factors. ${ }^{68}$

\section{Consumption and preference patterns}

Beverage consumption is influenced by many factors, including age, race, gender, dietary intake, eating behaviors and physical activity (Table 1$).^{71}$

There is some evidence that gender might have a different effect on preference for beverages. A study performed by 


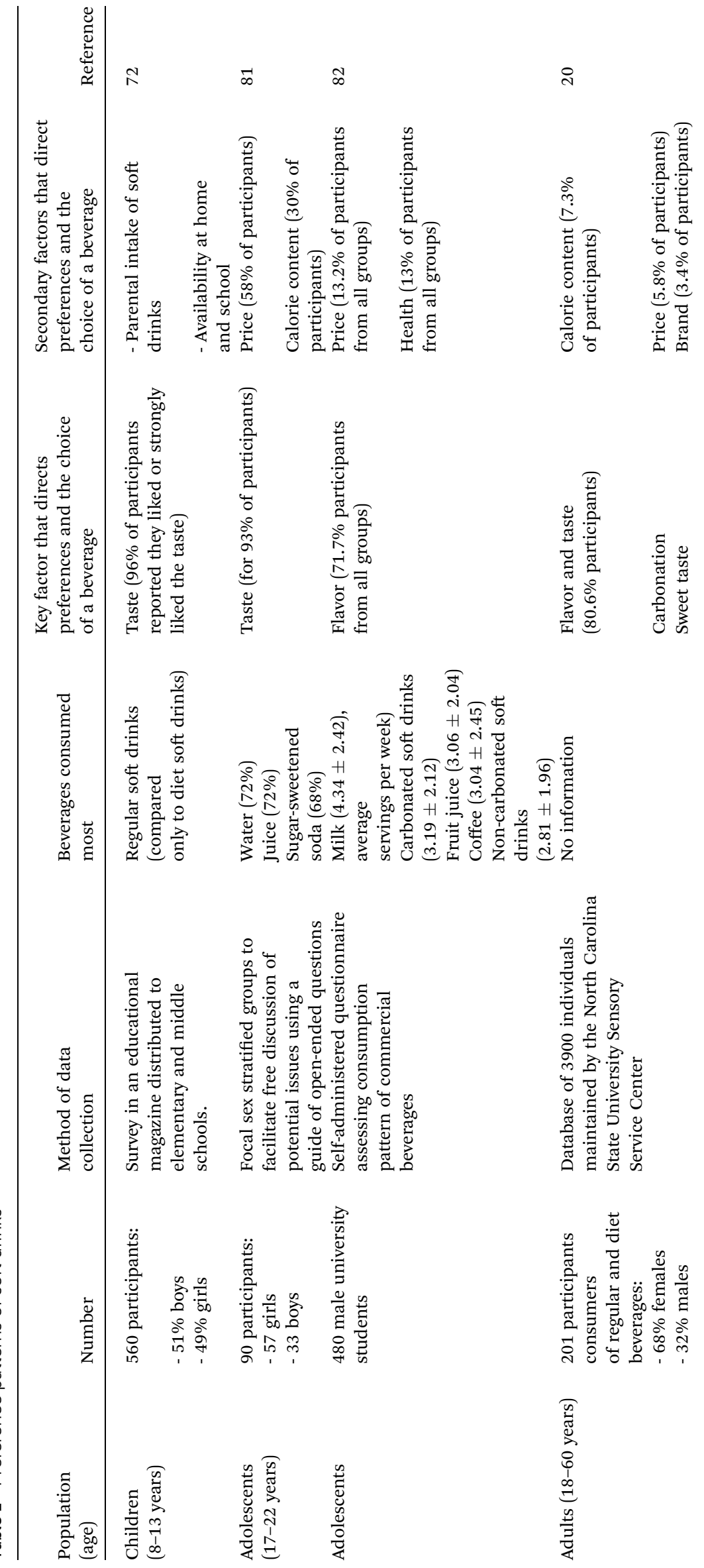


Grimm et $a l . .^{72}$ using a survey to report the frequency of consumption in 560 children showed that boys were more likely to report strongly liking the taste of soft drinks and their consumption was higher compared with that of the girls. This gender difference in terms of consumption was larger for regular than for diet soft drinks and larger at school than outside school in adolescents. ${ }^{72}$ In fact, girls with negative attitudes towards drinking regular soft drinks were more likely to believe that they would gain weight if they consumed regular soda. ${ }^{73}$ Whether beverage consumption refers to fluid milk, to fruit drinks, to citrus and non-citrus juices or to carbonated soft drinks, the trend is the same: boys of all ages drink more than girls do. ${ }^{71}$

With respect to differences by age, some studies have pointed out that the consumption of soft drinks increases from childhood to adolescence. Grimm et al. (2004) $)^{72}$ reported an increase of soft drink consumption in children from 8 to 13 years old. Similar results have been observed in a study performed according for the National Health and Nutrition Examination Survey, showing that the average consumption of regular carbonated beverages increases from childhood to young adolescence for both sexes, ${ }^{74}$ and the results also agree with those found by Vereecken et al. (2005), ${ }^{75}$ who found out that older pupils (15 years) consumed higher amounts of soft drinks than younger pupils (11-13 years). A reason for this might be the increasing opportunities for teenagers to purchase whatever they prefer outside home, since children are more dependent on their parents for intake of soft drinks and availability at home. ${ }^{72}$

The influence of both factors on the consumption of beverages were observed in a study performed in 4487 children aged between 2 and 16 years from Australia, using the Australian National Children's Nutrition and Physical Activity Survey to evaluate demographic, physical activity and dietary data from these volunteers. The results matched those obtained with the previously mentioned studies, showing that a high consumption of sugar sweetened beverages (more than one-third of daily beverage intake by volume) was associated with older age groups and males. ${ }^{76}$

Environmental factors, such as accessibility to drinks at home, at school and when shopping, parents' habits, imitation of peers and preferences are important determinants of soft drink consumption in childhood. ${ }^{77}$

\section{Environmental factors}

There are other important factors related to the increase of soft drink intake, such as the availability of soft drinks at home, at school or when shopping, and the portion size or the price of beverages. ${ }^{78}$ In addition, marketing also influences beverage consumption. Children (9-11 years) have been reported to rate a drink which has a label that is related to a healthy lifestyle as less pleasant compared to a one that is not labelled as healthy, showing that such a label for a novel drink would reduce the chance of it being liked. To the extent that taste governs preferences and consumption, the characterization of a food as healthy could reduce its anticipated pleasantness. ${ }^{79}$ In this respect, there is also an influence of commercial brands in the consumption of cola beverages. ${ }^{80}$

The home environment also has a strong influence on children's consumption of beverages. Parental practices serve as role models. In fact, those whose parents regularly drank soft drinks were almost three times more likely to drink this type of beverage five or more times per week compared with those whose parents did not regularly consume soft drinks. ${ }^{72}$ In addition, the parents are the ones deciding what foods and drinks should be available and accessible at home. ${ }^{71}$

\section{Preferences}

There is scarce information about the factors involved in children's soft drink consumption. In 2004 Grimm et al. ${ }^{72}$ showed the results observed in 560 children aged 8 to 13 years old who completed a survey and reported how often they drank soft drinks, the beverage type and taste preferences for these beverages. Possible answers included "strongly like", "like", "dislike" or "strongly dislike". The results revealed that $30 \%$ of children drank soft drinks daily, of which $85 \%$ reported that they usually drank regular soft drinks and only 15\% consumed diet soft drinks. The majority (96\%) reported that they liked or strongly liked the taste of soft drinks and this aspect was significantly associated with soft drink consumption. Those who reported that they "strongly like" the taste were 4.5 times more likely to drink this beverage five or more times per week, compared to those who reported "like", "dislike" or "strongly dislike" for the taste of soft drinks. This association between the "linking behavior" and the consumption of beverages could be influenced by psychological factors. To explore this, Sweetman et al. (2008) ${ }^{\mathbf{1 6}}$ performed a study in children aged 9-12 years using a scale of "Desire to Drink" (DD) in order to measure differences in the quantity and frequency with which children chose several beverages (water, sweetened soft drinks, low-calorie soft drinks, fruit squash, fruit juice and milk). This study allowed the relationship between DD and liking and consumption of these beverages to be evaluated. DD includes the following three items: "My child is always asking for a drink"; "If given the chance, my child would drink continuously throughout the day"; "If given the chance, my child would always be having a drink". Responses were scored from 1-5 ("never" to "always") and DD scores were obtained by calculating the mean of the three item responses, high scores meaning that there was a more frequent desire to have a drink, but not the type of beverage. A significant positive relationship was found between DD and preferences for milk, sweetened soft drinks and fruit squash, and DD was also related to more frequent consumption of sugar-sweetened and low calorie soft drinks, but not to the frequency of consumption of milk, fruit squash and fruit juice. These results show that children with a greater desire to drink consumed carbonated soft drinks more frequently than those with lower scores and had a stronger liking for sweetened soft drinks. ${ }^{16}$

Similar results have been found in 90 adolescents from the USA, with a mean age of 19 years, whose most commonly 
consumed beverages were water (72\%), juice (72\%) and sugarsweetened soda (68\%). Most of the participants reported that taste was an important factor in determining beverage choice (93\%), followed by price (58\%) and calorie content (30\%). Taste emerged as an essential reason for purchasing beverages, and certain beverages caused an 'addiction' because of the dominant effect of taste on the drinker's ability to stop drinking this type of beverage. Many of the students reported that "If it tastes good, I'm drinking it". Most students reported that given the choice between water and a beverage with flavor at the same price, they would always choose the flavored beverage. This choice of soft drinks can be due to the fact that adolescents avoid drinking water alone because of its lack of taste. In fact, they drink water only for hydration concerns and other beverages because of their taste. In this study there was a minority of students who regularly drank diet soft drinks because they preferred their taste rather than concerns about health or calories. However, most of the students reported that they strongly disliked the taste of diet beverages. ${ }^{81}$

Similar results have been found in a study performed in 480 male university students from Tokyo divided into three groups according to the average servings of commercial beverages consumed per week: rare consumption group (less than one beverage), moderate consumption group (1-3 beverages) and frequent consumption group (more than 4 beverages). Milk was the most consumed commercial beverage in all groups, followed by carbonated soft drinks, which were the favorite commercial beverage in the frequent and moderate consumption groups, unlike those in the rare consumption group. For all groups, the main reason to drink commercial beverages was to quench the thirst, followed by flavor in the moderate and frequent consumption group; and the most important factor for choosing a beverage over others was the flavor of the beverage in all groups $(71.7 \%$ of students in all groups), followed by price (13.2\%) and health concerns $(13 \%){ }^{82}$

A recent study performed in 201 adult consumers of lemon/ lime carbonated beverages revealed that for $80.6 \%$ of these consumers, the most important reason for purchasing beverages was flavor, followed by calorie content (7.3\%), price $(5.8 \%)$ and brand $(3.4 \%)$. Sodas with nutritive sweeteners had the highest numbers of likes in questions relating to preference for sweetness and preference for aftertaste, compared with nonnutritive beverages tested by regular and diet consumers. On the other hand, mouthfeel attributes associated with high carbonation (numbing, burn, bite) were the universal drivers for liking for these carbonated beverages. ${ }^{20}$ This outcome agrees with the pleasant sensation of effervescence found by people when carbonated beverages emerged around five decades ago. ${ }^{\mathbf{8 3}}$ These differentiating sensations are the major hedonic components contributing to the consumption of this type of beverage $^{49}$ and key attributes for flavor enhancement and a refreshing sensation. ${ }^{\mathbf{4 2}}$ Therefore, carbonation and sweetening systems highly affect consumer acceptability, carbonation being the principal attribute for driving consumers' preference patterns. $^{20}$

\section{Conclusion}

After reviewing all these concepts, taste and mouthfeel sensations are the main factors influencing a preference to choose a particular beverage and this is then related to its consumption, not only in childhood and youth, but also in adults. In this respect, these attributes could be used to influence the patterns of drinking beverages in order to improve liquid intake.

\section{Acknowledgements}

Funding by the "Asociacion de Bebidas Refrescantes" (ANFABRA).

\section{References}

1 B. M. Popkin, L. E. Armstrong, G. M. Bray, B. Caballero, F. Balz and W. C. Willet, A new proposed guidance system for beverage consumption in the United States, Am. J. Clin. Nutr., 2006, 83, 529-542.

2 A. J. Mitchel, in Formulation and production of carbonated soft drinks, ed. A. K. Mitchel, AVI, New York, 1990, p. 20.

3 L. Serra-Majem and A. Gil, Conclusions of the I International and III National Hydration Congress Madrid Spain 3rd and 4th December 2013, Rev. Esp. Nutr. Comunit., 2014, 20, 2-12.

$4 \mathrm{M}$. Shachman, in The soft drinks companion - a technical handbook for the beverage industry, CRC Press, Florida, 2005, p. 260.

5 B. M. Popkin, Patterns of beverage use across the lifecycle, Physiol. Behav., 2010, 100, 4-9.

6 K. J. Duffey and B. M. Popkin, Shifts in patterns and consumption of beverages between 1965 and 2002, Obesity, 2007, 15, 2739-2747.

7 K. J. Duffey, I. Huybrechts, T. Mouratidou, L. Libuda, M. Kersting, T. De Vriendt, F. Gottrand, K. Widhalm, J. Dallongeville, L. Hallström, M. González-Gross, S. De Henauw, L. A. Moreno and B. M. Popkin, HELENA Study group, Beverage consumption among European adolescents in the HELENA study, Eur. J. Clin. Nutr., 2012, 66, 244-252.

8 S. M. Shirreffs, Conference on "Multidisciplinary approaches to nutritional problems". Symposium on "Performance, exercise and health". Hydration, fluids and performance, Proc. Nutr. Soc., 2009, 68, 17.

9 E. Jequier and F. Constant, Water as an essential nutrient: the physiological basis of hydration, Eur. J. Clin. Nutr., 2010, 64, 115-123.

10 B. M. Popkin, K. E. D'Anci and I. H. Rosenberg, Water, hydration, and health, Nutr. Rev., 2010, 68, 439-458.

11 Panel on Dietetic Products, Nutrition, and Allergies (NDA), European Food Safety Authority (EFSA), Scientific Opinion on Dietary Reference Values for water, EFSA J., 2010, 8, 1459.

12 O. Malisova, V. Bountziouka, D. B. Panagiotakos, A. Zampelas and M. Kapsokefalou, The water balance questionnaire: design, reliability and validity of a questionnaire to evaluate water balance in the general population, Int. J. Food Sci. Nutr., 2012, 63, 138-44. 
13 S. Gibson and S. M. Shirreffs, Beverage consumption habits "24/7" among British adults: association with total water intake and energy intake, Nutr. J., 2013, 12, 9.

14 S. Nicolaidis, in Hydration throughout Life. Physiology of thirst, ed. M. J. Arnaud, John Libbey Eurotext, Montrouge, France, 1998, pp. 3-8.

15 H. Tuorila, R. M. Pangborn and H. G. Schutz, Choosing a beverage: comparison of preferences and beliefs related to the reported consumption of regular $v s$. diet sodas, Appetite, 1990, 14, 1-8.

16 C. Sweetman, J. Wardle and L. Cooke, Soft drinks and 'desire to drink' in preschoolers, Int. J. Behav. Nutr. Phys. Activ., 2008, 5, 60 .

17 M. Millard-Stafford, D. M. Wendland, N. K. O'Dea and T. L. Norman, Thirst and hydration status in everyday life, Nutr. Rev., 2012, 70, 147-151.

18 L. E. Armstrong, E. C. Johnson, A. L. McKenzie and C. X. Muñoz, Interpreting common hydration biomarkers on the basis of solute and water excretion, Eur. J. Clin. Nutr., 2013, 67, 249-253.

19 L. Hewson, T. Hollowood, S. Chandra and J. Hort, Tastearoma interactions in a citrus flavoured model beverage system: Similarities and differences between acid and sugar type, Food Qual. Prefer., 2008, 19, 323-334.

20 P. P. Leksrisompong, K. Lopetcharat, B. Guthrie and M. A. Drake, Preference mapping of lemon lime carbonated beverages with regular and diet beverage consumers, J. Food Sci., 2013, 78, S320-S328.

21 J. Chandrashekar, M. A. Hoon, N. J. P. Ryba and C. S. Zuker, The receptors and cells for mammalian taste, Nature, 2006, 444, 288-294.

22 P. A. Breslin and A. C. Spector, Mammalian taste perception, Curr. Biol., 2008, 18, 148-155.

23 A. Sclafani, Sweet taste signaling in the gut, Proc. Natl. Acad. Sci. U. S. A., 2007, 104, 14887-14888.

24 B. G. Green, Studying taste as a cutaneous sense, Food Qual. Prefer., 2003, 14, 99-109.

25 S. A. Simon, I. E. de Araujo, J. R. Stapleton and M. A. L. Nicolelis, Multisensory processing of gustatory stimuli, Chemosens. Percept., 2008, 1, 95-102.

26 S. A. Simon, I. de Araujo, R. Gutierrez and M. A. Nicolelis, The neural mechanisms of gustation: a distributed processing code, Nat. Rev. Neurosci., 2006, 7, 890-901.

$27 \mathrm{H}$. Abdi, What can cognitive psychology and sensory evaluation learn from each other?, Food Qual. Prefer., 2002, 13, 445-451.

28 American Society for Testing and Materials (ASTM), Standard definitions of terms relating to sensory evaluations of materials and products, 2005, pp. E253E255.

29 S. Arazi, D. Kilcast and W. M. Marrs, Hydrocolloid/sweetener systems: a multiple ingredient approach to improving the mouthfeel of low-calorie drinks, Leatherhead Res. Rep., 2001, 774, 1.

30 S. M. Kappes, S. J. Schmidt and S. Y. Lee, Descriptive Analysis of Cola and Lemon/Lime Carbonated Beverages, J. Food Sci., 2006, 71, S583-S589.
31 S. M. Kappes, S. J. Schmidt and S. Y. Lee, Relationship between physical properties and sensory attributes of carbonated beverages, J. Food Sci., 2007, 72, S001-S011.

32 S. Buhl, Application of pectins in soft drinks and beverages, Fruit Process., 1994, 4, 8.

33 M. M. Mozell, B. P. Smith, P. E. Smith, R. L. Sullivan and P. Swender, Nasal chemoreception in flavor identification, Arch. Otolaryngol., 1969, 90, 367-373.

34 E. R. Kandel, J. H. Schwartz and T. M. Jessell, in Principles of neural science, ed. E. R. Kandel, J. H. Schwartz and T. M Jessell, McGraw-Hill Professional, New York, 4 edn, 2000.

$35 \mathrm{~J}$. Delwiche, The impact of perceptual interactions on perceived flavor, Food Qual. Pref., 2004, 15, 137-146.

36 T. E. Rolls, in The brain and emotion, Oxford University Press, Oxford, 1999.

37 T. E. Rolls, H. Critchley, R. Mason and E. A. Wakeman, Orbitofrontal cortex neurons: role in olfactory and visual association learning, J. Neurophysiol., 1996, 75, 1970-1981.

38 H. N. Schifferstein and M. P. Cleiren, Capturing product experiences: A split-modality approach, Acta Psychol., 2005, 118, 293-318.

39 C. Da Porto, F. Cordaro and N. Marcassa, Effects of carbohydrate and noncarbohydrate sweeteners on the orange spirit volatile compounds, Food Sci. Technol., 2006, 39, 159-165.

40 S. Walker and J. Prescott, The influence of solution viscosity and different viscosifying agents on apple juice flavor, $J$. Sens. Stud., 2000, 15, 285-307.

41 P. Dalton, N. Doolittle, H. Nagata and P. A. S. Breslin, The merging of the senses: integration of subthreshold taste and smell, Nat. Neurosci., 2000, 3, 431-432.

42 A. Saint-Eve, I. Déléris, E. Aubin, E. Semon, G. Feron, J. M. Rabillier, D. Ibarra, E. Guichard and I. Souchon, Influence of composition ( $\mathrm{CO}_{2}$ and sugar $)$ on aroma release and perception of mint-flavored carbonated beverage, J. Agric. Food Chem., 2009, 57, 5891-5898.

43 A. Genovese, P. Piombino, A. Gambuti and L. Moio, Simulation of retronasal aroma of white and red wine in a model mouth system. Investigatingthe influence of saliva on volatile compound concentrations, Food Chem., 2009, 114, 100-107.

44 D. D. Muir, E. A. Hunter, S. A. R. Williams and R. M. Brennan, Sensory profiles of commercial fruit juice drinks: influence of sweetener type, J. Sci. Food Agric., 1998, 77, 559-565.

45 P. P. Leksrisompong, K. Lopetcharat, B. Gutthrie and M. A. Drake, Descriptive analysis of carbonated regular and diet lemon lime beverages, J. Sens. Stud., 2012, 27, 247-263.

46 National Academy of Sciences, Committee on Food Chemicals, Food chemicals codex, DC, NAS Press, Washington, 4th edn, 1996, pp. 52-53.

47 R. Keast and J. Roper, A complex relationship among chemical concentration, detection threshold, and suprathreshold intensity of bitter compounds, Chem. Senses, 2007, 32, 245-253.

48 B. M. King and J. Solms, Interactions of volatile flavor compounds with caffeine, chlorogenic acid and naringin, Proceedings Flavour, 1981, 81, 707-716. 
$49 \mathrm{~J}$. X. Guinard and R. Mazzuccheli, The sensory perception of texture and mouthfeel, Trends Food Sci. Technol., 1996, 7, 213-219.

50 B. G. Green, The effects of temperature and concentration on the perceived intensity and quality of carbonation, Chem. Senses, 1992, 17, 435-450.

51 N. J. N. Yau and M. R. McDaniel, The power function of carbonation, J. Sens. Stud., 1990, 5, 117-128.

52 J. M. Dessirier, C. T. Simons, M. I. Carstens, M. O'Mahony and E. Carstens, Psychophysical and neurobiological evidence that the oral sensation elicited by carbonated water is of chemogenic origin, Chem. Senses, 2000, 25, 277-284.

53 J. Frasnellia, C. Oehrn and M. Jones-Gotman, Effects of oral irritation on olfaction, Food Chem., 2009, 113, 1003-1007.

54 L. Hewson, T. Hollowood, S. Chandra and J. Hort, Gustatory, Olfactory and Trigeminal Interactions in a Model Carbonated Beverages, Chemosens. Percept., 2009, 2, 94-107.

55 C. Descoins, M. Mathlouthi, M. Le Moual and J. Hennequin, Carbonation monitoring of beverage in a laboratory scale unit with on-line measurement of dissolved $\mathrm{CO}_{2}$, Food Chem., 2006, 95, 541-553.

56 M. van Beilen, H. Bult, R. Renken, M. Stieger, S. Thumfart, F. Cornelissen and V. Kooijman, Effects of visual priming on taste-odor interaction, PLoS One, 2011, 6, e23857.

57 J. L. Johnson, E. Dzendolet and F. M. Clydesdale, Psychophysical relationships between sweetness and redness in strawberry-drinks, J. Food Prot., 1983, 46, 21-25.

58 L. M. Bartoshuk, K. Rennert, J. Rodin and J. C. Stevens, Effects of temperature on the perceived sweetness of sucrose, Physiol. Behav., 1982, 28, 905-910.

59 K. Talavera, Y. Ninomiya, C. Winkel, T. Voets and B. Nilius, Influence of temperature on taste perception, Cell. Mol. Life Sci., 2007, 64, 377-381.

60 J. A. Mennella, C. P. Jagnow and G. K. Beauchamp, Prenatal and postnatal flavor learning by human infants, Pediatrics, 2001, 107, E88.

61 M. I. Chuah and D. R. Zheng, Olfactory marker protein is present in olfactory receptor cells of human fetuses, Neuroscience, 1987, 23, 363-370.

62 A. W. Liley, in Pathophysiology of gestation, Vol. II: Fetal placental disorders. Disorders of amniotic fluid, ed. N. S. Assali, Academic Press, New York, 1972, p. 157.

$63 \mathrm{~J}$. A. Mennella and G. K. Beauchamp, Early flavor experiences: research update, Nutr. Rev., 1998, 56, 205-211.

64 J. E. Steiner, D. Glaser, M. E. Hawilo and K. C. Berridge, Comparative expression of hedonic impact: affective reactions to taste by human infants and other primates, Neurosci. Biobehav. Rev., 2001, 25, 53-74.

65 A. Drewnowski, J. A. Mennella, S. L. Johnson and F. Bellisle, Sweetness and food preference, J. Nutr., 2012, 142, 1142S-8S.

66 S. A. Sullivan and L. L. Birch, Infant Dietary Experience and Acceptance of Solid Foods, Pediatrics, 1994, 93, 271-277.

67 D. G. Liem and J. A. Mennella, Sweet and sour preferences during childhood: role of early experiences, Dev. Psychobiol., 2002, 41, 388-395.
68 L. L. Birch, Development of food preferences, Annu. Rev. Nutr., 1999, 19, 41-62.

69 D. G. Liem and C. de Graaf, Sweet and sour preferences in young children and adults: role of repeated exposure, Physiol. Behav., 2004, 83, 421-429.

70 F. Sartor, L. F. Donaldson, D. A. Markland, H. Loveday, M. J. Jackson and H. P. Kubis, Taste perception and implicit attitude toward sweet related to body mass index and soft drink supplementation, Appetite, 2011, 57, 237-246.

71 R. A. Forshee and M. L. Storey, Total beverage consumption and beverage choices among children and adolescents, Int. J. Food Sci. Nutr., 2003, 54, 297-307.

72 G. C. Grimm, L. Harnack and M. Story, Factors associated with soft drink consumption in school-aged children, $J$. Am. Diet. Assoc., 2004, 104, 1244-1249.

73 N. O. Kassem, J. W. Lee, N. N. Modeste and P. K. Johnston, Understanding soft drink consumption among female adolescents using the Theory of Planned Behavior, Health Educ. Res., 2003, 18, 278-291.

74 M. L. Storey, R. A. Forshee and P. A. Anderson, Beverage consumption in the US population, J. Am. Diet. Assoc., 2006, 106, 1992-2000.

75 C. Vereecken, J. Inchley, S. V. Subramanian, A. Hublet and L. Maes, The relative influence of individual and contextual socio-economic status on consumption of fruit and soft drinks among adolescents in Europe, Eur. J. Public Health, 2005, 15, 224-232.

76 K. Hafekost, F. Mitrou, D. Lawrence and S. Zubrick, Sugar sweetened beverage consumption by Australian children: Implications for public health strategy, BMC Public Health, 2011, 11, 950.

77 E. Bere, E. S. Glomnes, S. J. te Velde and K. I. Klepp, Determinants of adolescents' soft drink consumption, Public Health Nutr., 2008, 11, 49-56.

78 H. Debra, A. Rangan, J. Louie, V. Flood and T. Gil, Soft drinks, weight status and health: a review, NSW Centre for Public Health Nutrition, Sydney, 2009.

79 J. Wardle and G. Huon, An experimental investigation of the influence of health information on children's taste preferences, Health Educ. Res., 2000, 15, 39-44.

$80 \mathrm{M}$. Koenings and D. Tranel, Prefrontal cortex damage abolishes brand-cued changes in cola preference, Soc. Cogn. Affect Neurosci., 2008, 3, 1-6.

81 J. P. Block, M. W. Gillman, S. K. Linakis and R. E. Goldman, "If it tastes good, I'm drinking it": Qualitative Study of Beverage Consumption Among College Students, J. Adolesc. Health, 2013, 52, 702-706.

82 H. Kim, S. N. Han, K. Song and H. Lee, Lifestyle, dietary habits and consumption pattern of male university students according to the frequency of commercial beverage consumptions, Nutr. Res. Pract., 2011, 5, 124-131.

83 T. Johnson, L. Gerson, T. Hershcovici, C. Stave and R. Fass, Systematic review: the effects of carbonated beverages on gastro-oesophageal reflux disease, Aliment. Pharmacol. Ther., 2010, 31, 607-614. 